\title{
Promoter Methylation of Ezrin and its Impact on the Incidence and Prognosis of Cervical Cancer
}

\author{
Rui Qin Lu Cao Junrong Wang Junbao Liu \\ Department of Obstetrics and Gynecology, China-Japan Union Hospital of Jilin University, Changchun, \\ China
}

\section{Key Words}

Cervical cancer • Ezrin gene $•$ Methylation $•$ Incidence $•$ Prognosis

\begin{abstract}
Background/Aims: Aberrant localization and over-expression of Ezrin have been reported to be implicated in cervical cancer (CC). Aberrant promoter methylation of some gene families may serve as potential diagnostic biomarkers for CC. In this study, we explored the correlation of promoter methylation of the Ezrin gene with the incidence and prognosis of CC. Methods: Cervical tissues from a total of 483 patients with CC were collected from the China-Japan Union Hospital of Jilin University. Samples were assigned into four groups accordingly to pathological diagnosis, namely the control group, the cervical intraepithelial neoplasia (CIN) I group, the CIN II-III group and the CC group. Reverse transcription quantitative polymerase chain reaction (RT-qPCR) was performed to detect the mRNA expression of Ezrin. Methylationspecific polymerase chain reaction (MSP) was used to detect the promoter methylation of the Ezrin gene. The Kaplan-Meier product-limit method and the log-rank analysis were used for survival analysis, the Cox regression analysis for the prognostic factors for CC, and the logistic regression analysis for the risk factors for the occurrence of CC. Results: The methylation rate of the Ezrin gene was correspondingly increased from the control, the CIN I, the CIN II-III to the CC groups. Over-expressed mRNA of Ezrin was determined in CC tissues. The mRNA expression of Ezrin was correlated with tumor size, lymphatic metastasis, pathological grade and clinical stage (FIGO). The risk factors for the occurrence of CC were the number of abortions and the promoter methylation of the Ezrin gene. Poor prognosis of CC correlated to lymphatic metastasis, higher pathological grade, higher FIGO stage and positive Ezrin promoter methylation. Conclusion: These findings indicate that promoter methylation of the Ezrin gene may play a crucial role in carcinogenesis, progression and prognosis of CC.
\end{abstract}

\begin{tabular}{ll}
\hline Dr. Junbao Liu & Department of Obstetrics and Gynecology, China-Japan Union Hospital of Jilin University \\
& Xiantai Street 126, 130033 Changchun, Jilin Province (China) \\
& Tel. 86-431-84995181, E-Mail 413266497@qq.com
\end{tabular}




\section{Cellular Physiology Cell Physiol Biochem 2018;50:277-287 \begin{tabular}{ll|l} 
and Biochemistry & $\begin{array}{l}\text { DOI: 10.1159/000494005 } \\
\text { Published onlIne: 4 October 2018 }\end{array}$ & $\begin{array}{l}\text { C) } 2018 \text { The Author(s). Published by S. Karger AG, Basel } \\
\text { www.karger.com/cpb }\end{array}$ \\
\hline
\end{tabular} \\ Qin et al.: Ezrin Promoter Methylation and CC}

\section{Introduction}

Cervical cancer (CC) is one of the most common female tumors worldwide associated with poverty, race and health disparities [1]. Invasive CC is a major reason for female cancer death, leading to about 300, 000 deaths each year [2]. Human papillomavirus (HPV) infection is regarded as a main reason for CC and the most often detected types in CC are HPV16 (especially for squamous cell carcinoma) and HPV18 (especially for adenocarcinoma) [3]. However, only a small percentage of women infected with HPV develop CC. Other factors such as water-based metalworking fluids (MWF) may also increase the occurrence of CC [4]. Besides, cytokine gene polymorphisms have been related to the development of CC [5]. A previous study showed that nuclear factor-kappaB (NF- $\kappa \mathrm{B})$, a tumor promoter and a prognostic indicator, was associated with poor prognosis of CC [6].

Recently, the Ezrin gene has been found to aberrantly express in $\mathrm{CC}$ and been considered as an indicator of prognosis in early-stage CC [7]. As the first member of the Ezrin-RadixinMoesin (ERM) family, Ezrin is up-regulated in many tumors including pancreatic carcinoma, hepatocellular carcinoma, gastric cancer and breast cancer $[8,9]$. Ezrin is regarded as a scaffold protein which contributes to oncogenesis by linking cytoskeletal and membrane proteins [10]. Expression change of Ezrin is an independent prognostic factor in osteosarcoma [11]. DNA methylation is usually considered as a silencing epigenetic marker in diseases like cancer [12]. For example, the methylation of Dishevelled Binding Antagonist of Beta Catenin (DACT) 1and DACT 2 was associated with the development of esophageal squamous cell carcinoma (ESCC) and was regarded as prognostic biomarkers of ESCC [13]. Methylation of DNA repair gene 0-6-methylguanine-DNA methyltransferase (MGMT) promoter region has been correlated with better prognosis of glioblastoma multiforme [14]. Ezrin can promote cellular movement and motility as well as controlling cellular growth, whereby contributing to tumorigenesis, invasion, and metastasis [15]. Ezrin was previously found to be overexpressed in CC and its expression was actively involved in metastasis and poor prognosis [16]. Therefore, in the present study, we further investigate the correlation of promoter methylation of the Ezrin gene with the risk and prognosis of CC.

\section{Materials and Methods}

\section{Ethical statement}

The study protocol was approved by the Committee on the Ethics of China-Japan Union Hospital of Jilin University (No. 2009-01-15-18) and informed consent was obtained from each participant.

\section{Study subjects and grouping}

Cervical tissue specimens were collected from patients in Department of Gynecology and Obstetrics in the China-Japan Union Hospital of Jilin University between February 2010 and January 2013. Tissues from a total of 483 case were collected and were assigned into four groups, namely 137 cases in the control group (mean age, $49.63 \pm 5.26$ years), 117 cases in the cervical intraepithelial neoplasia (CIN) I group (mean age, $48.54 \pm 5.11$ years), 121 cases in the CIN II-III group (mean age, $48.11 \pm 4.50$ years) and 108 cases in the CC group (mean age, $49.72 \pm 5.25$ years).

\section{Inclusion/exclusion criteria and sample collection}

Sample collection strictly adhered to the inclusion criteria and the exclusion criteria. The CIN I, the CIN II-III and the CC groups included patients: (1) with complete clinical and pathological data; (2) with definite pathological results of CIN or CC; (3) who did not receive preoperative chemotherapy or radiotherapy. Patients were excluded from the CIN I, the CIN II-III and the CC groups if: (1) received cervical treatment within 3 months before operation, including vaginal medication, cryotherapy, and laser treatment; (2) were pregnant; (3) diagnosed with other gynecological malignancies, such as endometrial cancer, ovarian cancer and uterine sarcoma; and (4) diagnosed with other tumors, such as gastric cancer, colorectal cancer and breast cancer. The control group comprised cases: (1) who received total hysterectomy for benign uterine 


\section{Cellular Physiology Cell Physiol Biochem 2018;50:277-287 \begin{tabular}{ll|l} 
and Biochemistry Published onlIne: 4 October 2018 & $\begin{array}{l}\text { C } 2018 \text { The Author(s). Published by S. Karger AG, Basel } \\
\text { www.karger.com/cpb }\end{array}$ \\
\hline
\end{tabular} \\ Qin et al.: Ezrin Promoter Methylation and CC}

lesions; and (2) with no atypical squamous cells or cancer cells detected by Thinprep cytologic test (TCT). The exclusion criteria of the control group followed those of the CIN I, the CIN II-III and the CC groups. Collected samples were snap-frozen in Trizol and preserved at $-80^{\circ} \mathrm{C}$.

\section{Reverse transcription quantitative polymerase chain reaction ( $R T-q P C R$ )}

Frozen tissues were taken out from $-80^{\circ} \mathrm{C}(100 \mathrm{mg} / \mathrm{sample})$ and grinded according to the instructions for the Luna ${ }^{\circledR}$ Universal One-Step RT-qPCR Kit (New England Biolabs, Inc, US). The primers were designed and synthesized by Sangon Biotech Co., Ltd. (Shanghai, China). The reaction conditions for Ezrin were predenaturation at $94^{\circ} \mathrm{C}$ for $5 \mathrm{~min}$; 35 cycles of denaturation at $94^{\circ} \mathrm{C}$ for $45 \mathrm{~s}$, annealing at $67^{\circ} \mathrm{C}$ for $45 \mathrm{~s}$ and renaturation at $72^{\circ} \mathrm{C}$ for $45 \mathrm{~s}$; and extension at $72^{\circ} \mathrm{C}$ for $10 \mathrm{~min}$. The samples were stored at $-20^{\circ} \mathrm{C}$. The reaction conditions for $\beta$-actin were pre-denaturation at $94^{\circ} \mathrm{C}$ for $5 \mathrm{~min} ; 27$ cycles of denaturation at $94^{\circ} \mathrm{C}$ for $15 \mathrm{~s}$, annealing at $58^{\circ} \mathrm{C}$ for $45 \mathrm{~s}$ and renaturation at $72^{\circ} \mathrm{C}$ for $45 \mathrm{~s}$; and extension at $72^{\circ} \mathrm{C}$ for $10 \mathrm{~min}$. The IS 8900 gel imaging scanner was used to determine the gray values of paired samples of Ezrin and $\beta$-actin. The gray value ratio of the Ezrin and $\beta$-actin bands was considered as the mRNA expression of Ezrin. A higher ratio indicated higher mRNA expression of Ezrin.

\section{Methylation-specific polymerase chain reaction (MSP)}

The DNA in cervical tissues was extracted by phenol/chloroform extraction method and the qualified sample was stored at $-80^{\circ} \mathrm{C}$. According to the sequence of the Ezrin gene (Genebank Locus EF184645), the promoter is located in $1064 \mathrm{bp}-1459 \mathrm{bp}$. Based on the requirements of RT-qPCR primers in literature, the methylated (M) and unmethylated (U) primers of the Ezrin gene were designed by the Premier Primer 5.0 software (Premier, Canada). The primer sequences (Table 1) were synthetized by a commercial supplier (Beijing SBS Genetech Co., Ltd., Beijing, China). DNA modified by the methylation kit (Methylation-gold kitDNA, ZYMO-RESEARCH, US) was selected as the template DNA. The methylated and unmethylated primers were used to amplify the template DNA. The PCR amplification system $(50 \mu \mathrm{L})$ included $5 \mu \mathrm{L}$ of $10 \times$ PCR buffer treated with sodium bisulfite, $4 \mu \mathrm{L}$ of deoxy-ribonucleoside triphosphates (dNTPs), 0.5 $\mu \mathrm{L}$ of TaqDNA polymerase, $2.5 \mu \mathrm{L}$ of upstream primer, $2.5 \mu \mathrm{L}$ of downstream primer and $35.5 \mu \mathrm{L}$ of water. The methylated and unmethylated primers were used for PCR amplification. The reaction conditions for methylated primers were as follows: pre-denaturation at $94^{\circ} \mathrm{C}$ for $4 \mathrm{~min} ; 30$ cycles of denaturation at $94^{\circ} \mathrm{C}$ for $30 \mathrm{~s}$, annealing at $59^{\circ} \mathrm{C}$ for $45 \mathrm{~s}$, renaturation at $72^{\circ} \mathrm{C}$ for $45 \mathrm{~s}$; extension at $72^{\circ} \mathrm{C}$ for 7 min and finally stored at $4^{\circ} \mathrm{C}$. Amplified products of a volume of $5 \mu \mathrm{L}$ were used for electrophoresis on $2 \%$ agarose gel at $75 \mathrm{~V}$ for $20 \mathrm{~min}$. The results were observed and recorded by the UV transilluminator and the band of 153 bp was considered as positive band. The reaction conditions for unmethylated primers were as follows: pre-denaturation at $94^{\circ} \mathrm{C}$ for $4 \mathrm{~min} ; 30$ cycles of denaturation at $94^{\circ} \mathrm{C}$ for $30 \mathrm{~s}$, annealing at $53^{\circ} \mathrm{C}$ for $45 \mathrm{~s}$, and renaturation at $72^{\circ} \mathrm{C}$ for $45 \mathrm{~s}$; extension at $72^{\circ} \mathrm{C}$ for $7 \mathrm{~min}$ and finally stored at $4^{\circ} \mathrm{C}$. Amplified products of a volume of $5 \mu \mathrm{L}$ were used for electrophoresis on $2 \%$ agarose gel at $75 \mathrm{~V}$ for $20 \mathrm{~min}$. The results were observed and recorded by the UV transilluminator and the band of $153 \mathrm{bp}$ was considered as positive band.

\section{Follow-up}

Follow-ups ended on December 29, 2016. If patients were still alive by the end of follow-up, censored data were collected for analysis. Follow-ups were conducted via invited outpatient visits, telephone interviews or referring to medical records. The survival time of patients was recorded by using the overall survival (OS) for prognosis.

\section{Statistics}

Data were presented as mean values \pm standard deviations (SD). The Statistical Program for Social Sciences (SPSS) 20.0 software (SPSS, IBM, West Grove, PA, USA) was used for data analysis. The one-way analysis of variance (ANOVA) and the Kruskal-Wallis test were used to compare values among groups followed by the Student's t-test or the Mann-Whitney U-test to compare values between groups. The Tukey-
Table 1. Primer sequences for MSP and RT-qPCR. Note: MSP, methylation specific polymerase chain reaction; RT-qPCR, reverse transcription quantitative polymerase chain reaction

\begin{tabular}{lc}
\hline Primer & Sequence \\
\hline Ezrin-M & 5'-CTGGC AGCCC CGGGA AGTT-3' \\
& 5'-CCAGG ACAGC CAGCG CGAG-3' \\
Ezrin-U & 5'-TTGGT AGTTT TGGGA AGTT-3' \\
Ezrin (upstream) & 5'-CCAAAACAAC CAACA CAAA-3' \\
Ezrin (downstream) & '-GATGATGCGCGAGAAGGAGGAGTT-3' \\
$\beta$-actin (upstream) & 5'-GGGGCGGGGGTGCTGTCAT-3' \\
$\beta$-actin (downstream) & 5'-GGCTACAGCTTCACCACCAC-3' \\
\hline
\end{tabular}


Kramer test or the Steel test was also used depending on the distribution of data. The Pearson correlation analysis was carried out for the analysis of the correlation of two variable quantities. The Kaplan-Meier product-limit method was used for survival analysis. Comparison of survival time was conducted by the Log-rank analysis. The Cox regression analysis was used to analyze the prognostic factors. All tests were two-tailed, with the significance level set to $P<0.05$.

\section{Results}

Age of menarche, menstrual cycle and the number of abortions correlate to the occurrence of CC

Baseline clinical data of the four groups were compared to assess the risk factors of CC. Significant differences in the age of menarche, menstrual cycle and the number of abortions were seen among the control, the CIN I, the CIN II-III and the CC groups (all $p<0.05$ ) (Table 2 ). These results demonstrated that $\mathrm{CC}$ correlated with age of menarche, menstrual cycle and the number of abortions. Insignificant differences in age, marital history, smoking and drinking habits, menstrual period and fertility were noted among the control, the CIN I, the CIN II-III and the CC groups (all $p>0.05$ ).

Over-expressed Ezrin mRNA is associated with the development of CC

RT-qPCR was applied to determine the mRNA expression of Ezrin. mRNA expression of Ezrin was different among the control, the CIN I, the CIN II-III and the CC groups. The mRNA expression of Ezrin in the CC group was significantly higher than that in the control, the CIN I and the CIN II-III groups (all $p<$ 0.05) (Fig. 1). The mRNA expression of Ezrin was not associated with age, pathological type and focus type of the patients (all $p>$ 0.05 ). However, the mRNA
Table 2. Clinical data of the control, CIN I, CIN II-III and CC groups. The one-way analysis of variance (ANOVA) was used to compare values among groups. Note: CIN, cervical intraepithelial neoplasia; CC, cervical cancer

\begin{tabular}{lccccc}
\hline Characteristics & control & CIN I & CIN II-III & CC & p values \\
\hline Case & 137 & 117 & 121 & 108 & \\
Age (years) & $49.6 \pm 5.3$ & $48.54 \pm 5.1$ & $48.1 \pm 4.5$ & $49.7 \pm 5.3$ & 0.352 \\
Married (years) & $23.2 \pm 1.9$ & $22.9 \pm 1.8$ & $23.1 \pm 2.2$ & $23.3 \pm 1.7$ & 0.433 \\
Smoking (n, \%) & $10(7.3)$ & $5(4.3)$ & $11(9.1)$ & $9(8.3)$ & 0.505 \\
Drinking (n, \%) & $22(16.1)$ & $16(13.7)$ & $16(13.2)$ & $17(15.7)$ & 0.906 \\
Age of menarche (years) & & & & & \\
$<14$ (n, \%) & $42(30.7)$ & $42(35.9)$ & $50(41.3)$ & $53(49.1)$ & 0.025 \\
$\geq 14$ (n, \%) & $95(69.3)$ & $75(64.1)$ & $71(58.7)$ & $55(50.9)$ & \\
Period (days) & & & & \\
$<5$ (n, \%) & $9(6.6)$ & $5(4.3)$ & $10(8.3)$ & $8(7.4)$ & \\
$\leq 5<7$ (n, \%) & $108(78.8)$ & $102(87.2)$ & $102(84.3)$ & $91(84.3)$ & 0.382 \\
$\geq 7$ (n, \%) & $20(14.6)$ & $10(8.5)$ & $9(7.4)$ & $9(8.3)$ & \\
Menstrual cycle (days) & & & & \\
$<26$ (n, \%) & $12(8.8)$ & $5(4.3)$ & $6(5.0)$ & $3(2.8)$ & \\
$\leq 26<30$ (n, \%) & $96(70.1)$ & $75(64.1)$ & $92(76.0)$ & $87(80.6)$ & 0.032 \\
$\geq 30$ (n, \%) & $29(21.2)$ & $37(31.6)$ & $23(19.0)$ & $18(16.7)$ & \\
Abortion (time) & & & & & \\
$<1$ (n, \%) & $32(23.4)$ & $28(23.9)$ & $31(25.6)$ & $12(11.1)$ & \\
$1-2$ (n, \%) & $82(59.9)$ & $68(58.1)$ & $56(46.3)$ & $55(50.9)$ & 0.001 \\
$\geq 3$ (n, \%) & $23(16.8)$ & $21(17.9)$ & $34(28.1)$ & $41(38.0)$ & \\
Children (NO.) & & & & & \\
$\leq 1$ (n, \%) & $59(43.1)$ & $51(43.6)$ & $62(51.2)$ & $41(38.0)$ & 0.238 \\
$\geq 2$ (n, \%) & $78(56.9)$ & $66(56.4)$ & $59(48.8)$ & $67(62.0)$ & \\
\hline
\end{tabular}

Fig. 1. Increased Ezrin mRNA expression is observed in CC tissues. RT-qPCR was applied to determine the mRNA expression of Ezrin. The mRNA expression of Ezrin in the CC group was significantly higher than that in the control group but not than that in the CIN I and the CIN II-III groups. ${ }^{*}, \mathrm{p}<0.05$, compared with the control group; CIN, cervical intraepithelial neoplasia; CC, cervical cancer; RT-qPCR, reverse transcription quantitative polymerase chain reaction.

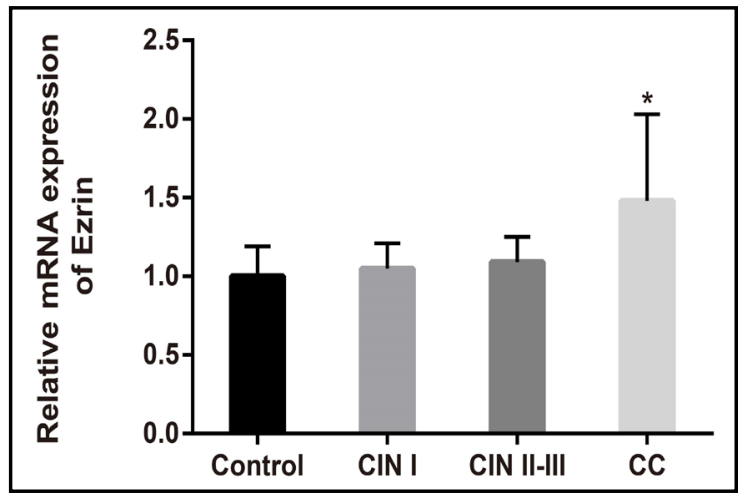


expression of Ezrin was correlated with lymphatic metastasis, pathological grade, clinical stage (FIGO) and tumor size (all $p<0.05$ ) (Table 3). These findings indicated that over-expression of Ezrin mRNA might be involved in the development of CC.

\section{Promotermethylation} of the Ezrin gene may contribute to the development of CC

To assess whether

Ezrin promoter methylation is related to CC, PCR products of the control, the CIN I, the CIN II-III and the CC groups were detected by MSP. Our results showed that the $M$ primers were negative and the $U$ primers were positive in the control group, indicating that methylation was absent in normal tissues. In the $\mathrm{CC}$ group, the $\mathrm{M}$ primers were positive and the $U$ primers were negative, showing that methylation occurred in the CC group (Fig. 2A). In the CIN I and the CIN II-III groups, the $\mathrm{M}$ and the $\mathrm{U}$ primers were both positive, indicating that partial methylation occurred in both groups (Fig. 2B). The methylation proportions were $0,18 \%, 29 \%$ and $86 \%$, respectively in the control, the CIN I, the CIN II-III and the CC groups, and the difference was statistically significant (all $p<0.05$ ). Significant difference of the methylation proportions was seen among the CIN I, the CIN II-III and the CC groups (Control $<$ CIN I $<$ CIN II and III $<$ CC for amplified products of methylated primers, and Control $>$ CIN I $>$ CIN II and III $>$ CC for amplified products of unmethylated primers, all $p<0.05$ ) (Table 4). Thus, methylation of the
Table 3. Relationship between mRNA expression of Ezrin and clinical pathological features of patients with CC. The one-way analysis of variance (ANOVA) was used to compare values among groups followed by the Student's t-test or the Mann-Whitney U-test to compare values between groups. Note: SD, standard deviation; CC, cervical cancer

\begin{tabular}{lcccc}
\hline Clinical parameters & Items & $\mathrm{n}$ & mean \pm SD & p values \\
\hline \multirow{2}{*}{ Age } & $<50$ & 53 & $1.56 \pm 0.53$ & \multirow{2}{*}{0.142} \\
& $\geq 50$ & 55 & $1.40 \pm 0.57$ & \\
Lymphatic metastasis & No & 60 & $1.38 \pm 0.55$ & 0.041 \\
& Yes & 48 & $1.60 \pm 0.53$ & \\
Pathological type & Squamous cancer & 57 & $1.53 \pm 0.53$ & \multirow{2}{*}{0.334} \\
& Glandular cancer + adenosquamous cancer & 51 & $1.43 \pm 0.58$ & \\
Pathological grade & High & 17 & $1.15 \pm 0.51$ & \\
& Moderately & 42 & $1.45 \pm 0.59$ & 0.008 \\
FIGO stage & Poorly & 49 & $1.62 \pm 0.48$ & \\
& Ib stage & 43 & $1.34 \pm 0.58$ & \\
Tumor size & Il a stage & 35 & $1.49 \pm 0.52$ & 0.022 \\
& II b stage & 30 & $1.67 \pm 0.50$ & \\
Focus type & S4 cm & 66 & $1.39 \pm 0.58$ & \multirow{2}{*}{0.044} \\
& $>4$ cm & 42 & $1.61 \pm 0.49$ & \\
& Exogenous & 22 & $1.54 \pm 0.40$ & \\
& Endogenous & 30 & $1.34 \pm 0.69$ & \multirow{2}{*}{0.239} \\
& Ulcerative & 27 & $1.43 \pm 0.50$ & \\
& Rigid tube & 29 & $1.62 \pm 0.51$ & \\
\hline
\end{tabular}

Fig. 2. Ezrin $\mathrm{p} r$ o $\mathrm{m}$ o $\mathrm{t}$ e $\mathrm{r}$ methylation correlates to the occurrence of CC. The M primers are negative and the $U$ primers were positive in the control group while the M primers are positive and $\mathrm{U}$ primers are negative in the CC group (2A). The $M$ and the $\mathrm{U}$ primers are both positive in the CIN I and the CIN II-III groups (2B). M, amplified products of methylated

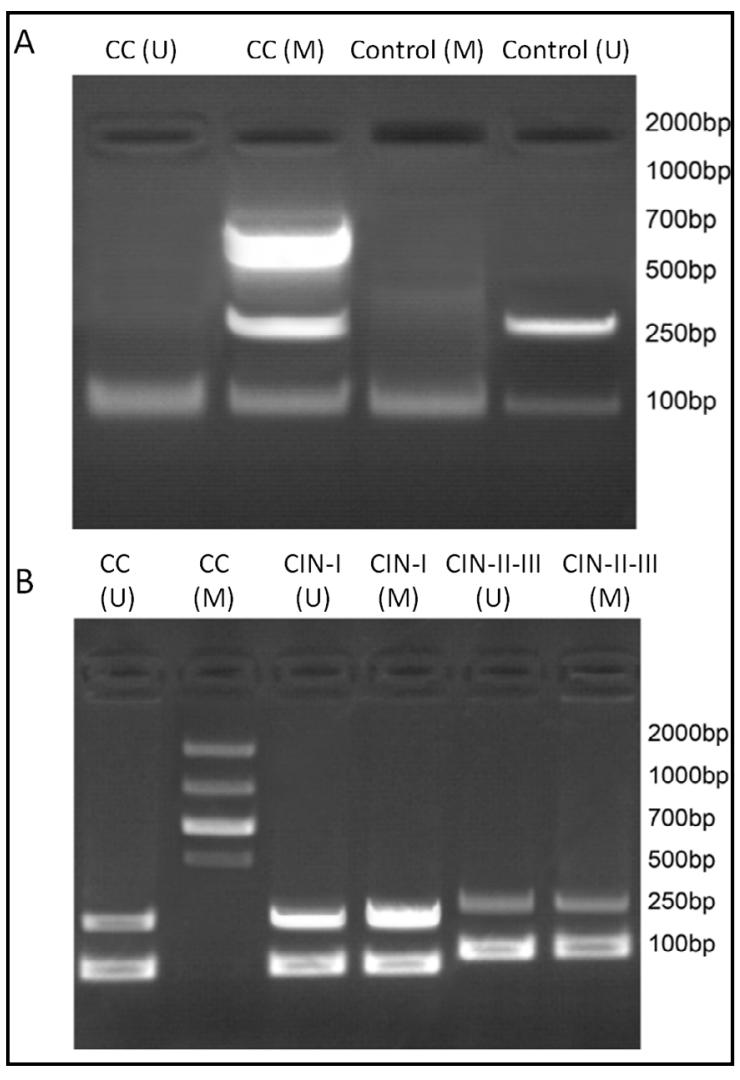
primers; U, amplified products of unmethylated primers; CIN, cervical intraepithelial neoplasia; CC, cervical cancer. 
Ezrin promoter is correlated with the development and progression of CC.

\section{Independent risk factors for CC includes the number of abortions and Ezrin promoter methylation}

The logistic regression analysis was conducted to assess the risk factors for the occurrence of CC. The input method was used for the binary logistic regression analysis with CC as the dependent variable and the age of menarche, menstrual cycle, the number of abortions and the Ezrin promoter methylation as independent variables. We showed that the number of abortions and Ezrin promoter methylation were independent risk factors for CC (all $p<0.05$ ) (Table 5). Thus, the occurrence of CC has two risk factors, including the number of abortions and the Ezrin promoter methylation.

Poor survival of CC is associated with higher FIGO stage, larger tumor size, lymphatic metastasis and Ezrin promoter methylation

To evaluate the survival of $\mathrm{CC}$, the log-rank analysis was used to compare survival rate among the control, the CIN I, the CIN II-III and the CC groups. The median survival time of all patients with CC was 27 months. The survival rate was $63.64 \%$ in 3 years. Significant differences were found in the survival rates of patients with different FIGO stage, Ezrin methylation, tumor size and lymphatic metastasis (all $p<0.05$ ) (Fig. 3). The survival rate decreased with higher FIGO stage, larger tumor size, lymphatic metastasis or Ezrin promoter methylation. These results suggest that higher FIGO stage, larger tumor size lymphatic metastasis and Ezrin promoter methylation are associated with poor survival of CC. No significant differences in survival rate were seen among patients with different age, pathological grade, pathological type and focus type (all $p>0.05$ ).

Lymphatic metastasis, pathological grade, FIGO stage and Ezrin promoter methylation associated with poor prognosis of CC

The Cox regression model was used for multivariate analysis of risk factors for prognosis of CC. The tumor size, lymphatic metastasis, pathological grade, FIGO stage, and methylation of Ezrin gene were included for analysis of the Cox regression model. We found that tumor size $(p>0.05)$ was not an independent prognostic factor for patients with CC while lymphatic metastasis $(p=0.033)$, pathological grade $(p=0.045)$, FIGO stage $(p=0.034)$ and Ezrin methylation $(p=0.006)$ were independent prognostic factors (Table 5). Therefore, poor prognosis of CC correlates to lymphatic metastasis, pathological grade, FIGO stage and Ezrin promoter methylation (Table 6).

\section{Discussion}

In the present study, we explored the correlation of promoter methylation of the Ezrin gene with the risk and prognosis of CC. We found that CC correlated with age of menarche, menstrual cycle and the number of abortions, while not with age, marital history, smoking and drinking habits, menstrual period and fertility. We also found that the mRNA expression and 
Fig. 3. Single factors of 3-year survival rate of CC. Ezrin methylation is negatively correlated with 3-year survival rate of $\mathrm{CC}$ (3A); age is not correlated with 3-year survival rate of CC (3B); pathological grade is not correlated with 3-year survival rate of $\mathrm{CC}$ (3C); FIGO stage is negatively correlated with 3-year survival rate of CC (3D); tumor size is negatively correlated with 3-year survival rate of CC (3E); pathological type is not correlated with 3-year survival rate of CC (3F); lymphatic metastasis is correlated with lower 3-year survival rate of CC (3G); focus type is not correlated with 3-year survival rate of CC (3H). CC, cervical cancer.
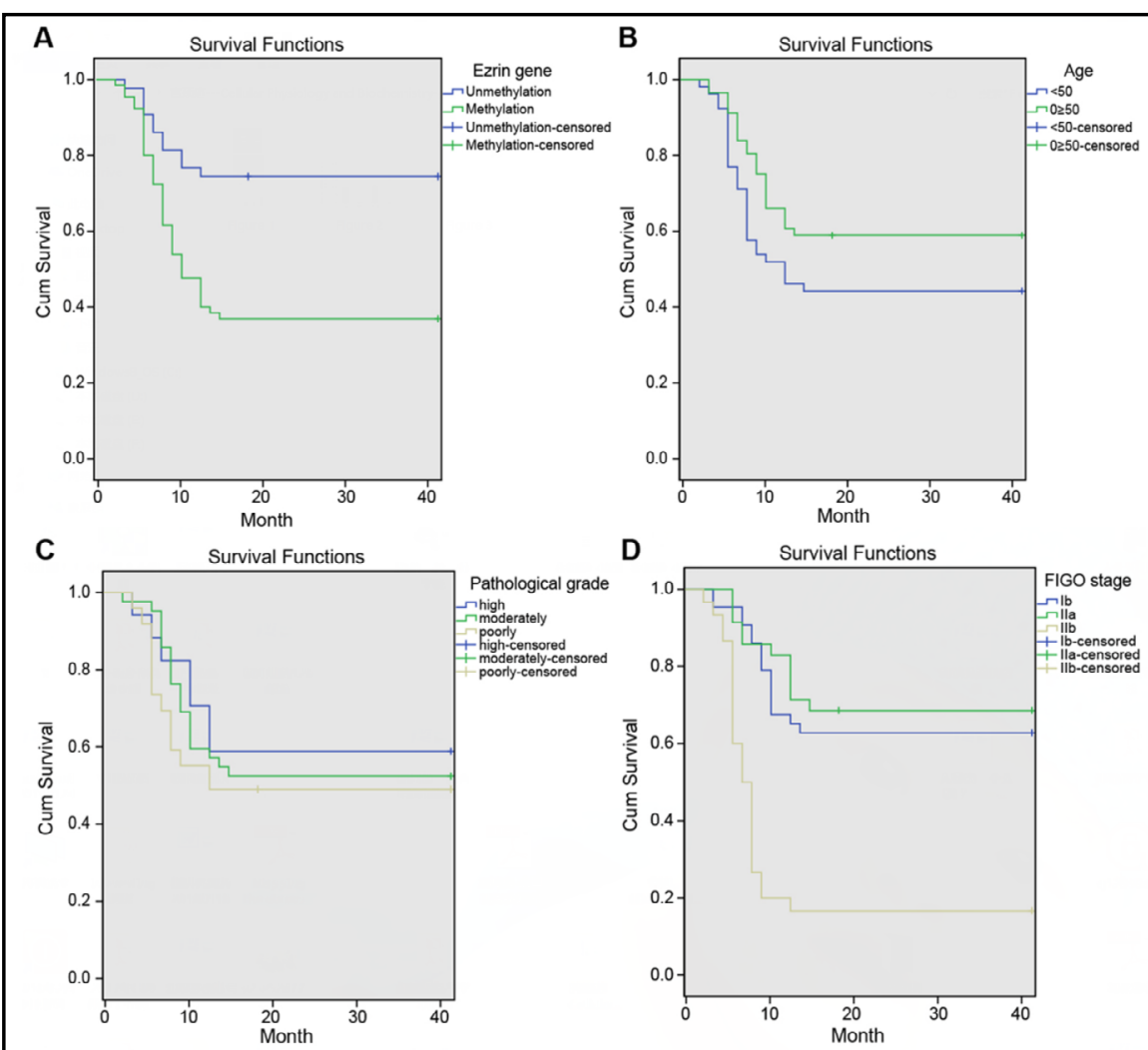

D
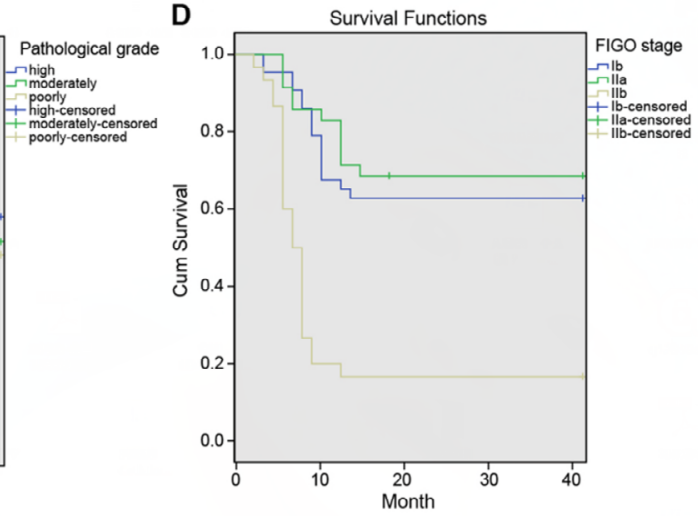

E
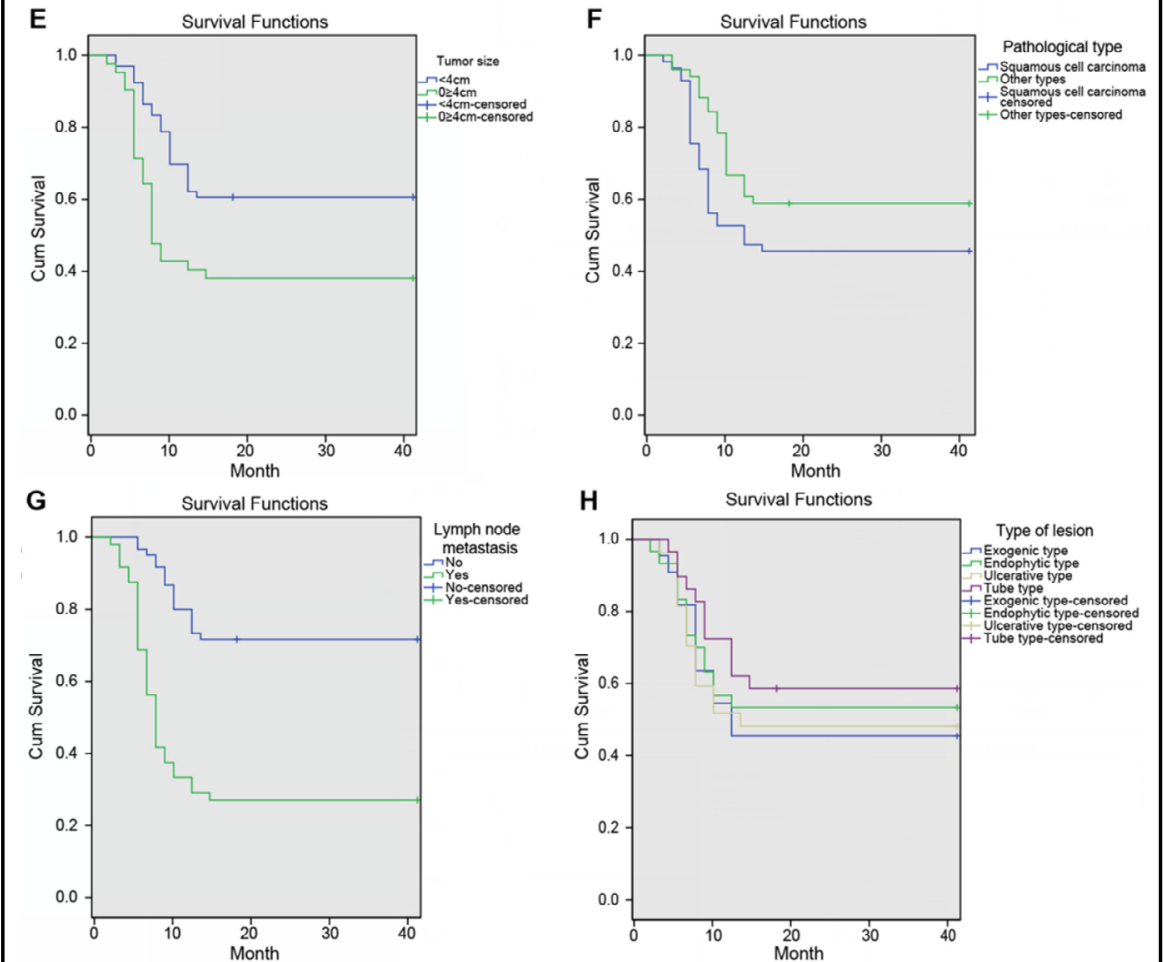
the promoter methylation rate of the Ezrin gene were up-regulated in CC and were related to the risk and prognosis of CC. Our findings suggest that promoter methylation of the Ezrin gene may play a crucial role in carcinogenesis, development and progression of CC.

CC leads to hundreds of thousands of women deaths worldwide each year [17]. The prognosis of advanced and recurrent CC is still under poor control [18]. Despite first-line therapeutic strategies for CC including radiotherapy, chemotherapy and surgery, the 5-year survival rate for patients with advanced CC is far from satisfactory [19]. DNA methylation has been associated with genetic loss of functional mutations [20]. DNA methylation is also one of the most frequent molecular alterations in human cancers like colorectal cancer [21]. For example, distinctive patterns of $\mathrm{CpG}$ island hypermethylation are correlated with the prognosis of CC [20]. We therefore focused on the promoter methylation of the Ezrin gene in our study.

One of our main findings was that mRNA expression of the Ezrin gene were upregulated in CC tissues. Results from a previous study indicated the correlation of promoter methylation of the p16, the DAPK, the CDH1, and the TIMP-3 genes with the histologic type and stage of CC [22]. Moreover, another study showed that promoter methylation of SFRPs gene family was correlated with the development of CC, which could be regarded as molecular biomarker for the screening of CC [23]. The Ezrin gene was up-regulated in many tumors such as pancreatic carcinoma, hepatocellular carcinoma, gastric cancer and breast cancer, and the up-regulation of the Ezrin gene might enhance the metastatic phenotype of tumors $[8,9]$. Since the Ezrin gene takes part in cell migration and cell recognition through the immune system, it may exert an direct effect on tumor progression [24]. Consistent with our results, Ezrin expression was reported to be upregulated in CC and cervical intraepithelial neoplasia tissues $[7,25]$. We revealed that the mRNA expression of the Ezrin gene was markedly increased in the CC group. As a membrane-cytoskeleton crosslinking protein and tumor promoter, expression of Ezrin is known to be positively correlated with degree of malignancy in many tumors, and to be a risk factor for these cancers including breast cancer and endometrium cancer [16]. Moreover, the Ezrin gene plays a crucial role in the metastasis of tumors [26]. Ezrin also played a crucial role in the growth of cancer cells. As previously demonstrated, mRNA expression of the Ezrin gene is obviously increased in the osteosarcoma (OS) cell lines, which may be associated with the rapid proliferation of OS cells [27]. Moreover, the expression of Ezrin was significantly increased in lung cancer, indicative of its involvement in controlling the biological behavior of lung cancer [28]. Since Ezrin expression levels were closely related to metastatic tendency in various cancers, Ezrin over-expression indicated a poor prognosis of myxofibrosarcomas, which may provide a potential value in the prediction of tumor aggressiveness [29]. As compared with the late stage patients with CC and lymph node metastasis-positive patients, the equivalent early stage patients had significantly reduced expressions of Ezrin mRNA and protein [30].

Another main findings of our study was that the promoter methylation of the Ezrin gene was markedly increased in CC. Importantly, no promoter methylation of the Ezrin gene was noted at all in the control group. Interestingly, methylation of $\mathrm{CpG}$ islands within gene promoter regions could result in silencing of gene expression and methylation of tumorrelevant genes occurred in numerous cancers [31]. For example, methylation of the ESR1 promoter was related to higher tumor grading of patients with CC [32]. CpG promoter methylation could result in GPX3 (a possible tumor suppressor) downregulation in CC [33]. The methylation of APC1A promoter was also closely correlated with biological features in 


\section{Cellular Physiology Cell Physiol Biochem 2018;50:277-287 \begin{tabular}{l|l} 
DOI: 10.1159/000494005 & $\begin{array}{l}\text { O } 2018 \text { The Author(s). Published by S. Karger AG, Basel } \\
\text { www.karger.com/cpb }\end{array}$ \\
\hline
\end{tabular} \\ Qin et al.: Ezrin Promoter Methylation and CC}

CC and could therefore be used to predict poor prognosis of CC [34]. DNA methylation could result in carcinogenesis through silencing important tumor suppressor genes and aberrant methylation of tumor suppressor genes could be regarded as a prognostic and predictive biomarker for cancer [35]. An increase in the promotor methylation of Ezrin in CC cases would normally cause a decrease in gene transcription. However, SET and MYND domaincontaining protein 3 (SMYD3), a methyltransferase, regulates transcription of EZR and LOXL2 by directly binding to the sequences of the promoter regions of these target genes in esophageal squamous cell carcinoma [36].

We also showed that FIGO stage, pathological grade, lymphatic metastasis, and promoter methylation of the Ezrin gene were independent risk factors for the prognosis of CC. Since invasion of the uterine body was related to nodal metastasis, lymphatic metastasis was an important prognostic factor for the relapse and survival of patients with invasive CC [37]. Patients without lymphatic metastasis had a decreased risk of recurrence [38], and thus lymphatic status may serve as a significant prognostic factor in patients with CC [39]. The FIGO stage has been widely used for staging CC because the recurrence rate and prognosis were directly correlated with the degree of tumor spread at the initial stageand it was considered as an important prognostic factor for the prediction of recurrence and long-term outcomes [40].

Our study has several limitations. Firstly, due to the relatively small sample size and short duration of follow-ups, our results lacked sufficient statistical power to assess the exact roles of Ezrin promoter methylation in the development and progression of CC. Secondly, because of the limitation of insufficient data, we failed to explore the correlation of Ezrin promoter methylation with other clinicopathological features, such as tumor grade and TNM stage. Lastly, the follows-up were conducted via invited outpatient visits, telephone interviews or referring to medical records. As a consequence, data collection might be insufficient due to the short follow-up period and the variable follow-up approaches. Therefore, further studies with a larger sample size and longer follow-ups are warranted for a more comprehensive understanding of promoter methylation of Ezrin in CC.

\section{Conclusion}

Our study provided evidence that patients with CC had increased mRNA expression and promoter methylation rate of the Ezrin gene; the Ezrin promoter methylation was associated with the risk and the prognosis of CC. Further studies are needed to elucidate the underlying mechanisms.

\section{Acknowledgements}

The study was supported by fundings from Jilin University.

\section{Disclosure Statement}

The authors declare to have no competing interests.

\section{References}

1 Scarinci IC, Garcia F A, Kobetz E, Partridge EE, Brandt HM, Bell MC, Dignan M, Ma GX, Daye JL, Castle PE: Cervical cancer prevention: new tools and old barriers. Cancer 2010;116:2531-2542.

- Hu X, Schwarz JK, Lewis JS Jr., Huettner PC, Rader J S, Deasy J O, Grigsby PW, Wang X: A microRNA expression signature for cervical cancer prognosis. Cancer Res 2010;70:1441-1448. 


\section{Cellular Physiology Cell Physiol Biochem 2018;50:277-287 \begin{tabular}{ll|l} 
and BiOChemistry & DOI: 10.1159/000494005 & $\begin{array}{l}\text { C } 2018 \text { The Author(s). Published by S. Karger AG, Basel } \\
\text { www.karger.com/cpb }\end{array}$
\end{tabular} \\ Qin et al.: Ezrin Promoter Methylation and CC}

3 Arnheim Dahlstrom L, Andersson K, Luostarinen T, Thoresen S, Ogmundsdottir H, Tryggvadottir L, Wiklund F, Skare GB, Eklund C, Sjolin K, Jellum E, Koskela P, Wadell G, Lehtinen M, Dillner J: Prospective seroepidemiologic study of human papillomavirus and other risk factors in cervical cancer. Cancer Epidemiol Biomarkers Prev 2011;20:2541-2550.

-4 Betenia N, Costello S and Eisen EA: Risk of cervical cancer among female autoworkers exposed to metalworking fluids. Scand J Work Environ Health 2012;38:78-83.

5 Barbisan G, Perez LO, Contreras A, Golijow CD: TNF-alpha and IL-10 promoter polymorphisms, HPV infection, and cervical cancer risk. Tumour Biol 2012;33:1549-1556.

-6 Li J, Jia H, Xie L, Wang X, Wang X, He H, Lin Y, Hu L: Association of constitutive nuclear factor-kappaB activation with aggressive aspects and poor prognosis in cervical cancer. Int J Gynecol Cancer 2009;19:1421-1426.

7 Tan J, Zhang C, Qian J: Expression and significance of Six1 and Ezrin in cervical cancer tissue. Tumour Biol 2011;32:1241-1247.

-8 Yu Y, Zeng P, Xiong J, Liu Z, Berger S L, Merlino G: Epigenetic drugs can stimulate metastasis through enhanced expression of the pro-metastatic Ezrin gene. PLoS One 2010;5:e12710.

-9 Jin J, Jin T, Quan M, Piao Y, Lin Z: Ezrin overexpression predicts the poor prognosis of gastric adenocarcinoma. Diagn Pathol 2012;7:135.

10 Saygideger-Kont Y, Minas T Z, Jones H, Hour S, Celik H, Temel I, Han J, Atabey N, Erkizan H V, Toretsky J A and Uren A: Ezrin Enhances EGFR Signaling and Modulates Erlotinib Sensitivity in Non-Small Cell Lung Cancer Cells. Neoplasia 2016;18:111-120.

11 Wang Z, He ML, Zhao JM, Qing HH, Wu Y: Meta-analysis of associations of the ezrin gene with human osteosarcoma response to chemotherapy and prognosis. Asian Pac J Cancer Prev 2013;14:2753-2758.

12 Jones P A: Functions of DNA methylation: islands, start sites, gene bodies and beyond. Nat Rev Genet 2012;13:484-492.

13 Guo YL, Shan BE, Guo W, Dong ZM, Zhou Z, Shen SP, Guo X, Liang J, Kuang G: Aberrant methylation of DACT1 and DACT2 are associated with tumor progression and poor prognosis in esophageal squamous cell carcinoma. J Biomed Sci 2017;24:6.

14 Srivastava A, Jain A, Jha P, Suri V, Sharma MC, Mallick S, Puri T, Gupta DK, Gupta A, Sarkar C: MGMT gene promoter methylation in pediatric glioblastomas. Childs Nerv Syst 2010;26:1613-1618.

15 Fadiel A, Choi SD, Park B, Kim TH, Buldo-Licciardi J, Ahmadi M, Arslan A, Mittal K, Naftolin F: Expression of Ezrin and Estrogen Receptors During Cervical Carcinogenesis. Reprod Sci 2017;24:706-712.

16 Kong J, Di C, Piao J, Sun J, Han L, Chen L, Yan G, Lin Z: Ezrin contributes to cervical cancer progression through induction of epithelial-mesenchymal transition. Oncotarget 2016;7:19631-19642.

17 Paradkar PH, Joshi JV, Mertia PN, Agashe SV, Vaidya RA: Role of cytokines in genesis, progression and prognosis of cervical cancer. Asian Pac J Cancer Prev 2014;15:3851-3864.

-18 Kim HS, Yoon G, Ryu JY, Cho YJ, Choi JJ, Lee YY, Kim TJ, Choi CH, Song S Y, Kim B G, Bae D S and Lee J W: Sphingosine kinase 1 is a reliable prognostic factor and a novel therapeutic target for uterine cervical cancer. Oncotarget 2015;6:26746-26756.

-19 Fan Z, Cui H, Xu X, Lin Z, Zhang X, Kang L, Han B, Meng J, Yan Z, Yan X, Jiao S: MiR-125a suppresses tumor growth, invasion and metastasis in cervical cancer by targeting STAT3. Oncotarget 2015;6:25266-25280.

20 Kordi Tamandani DM, Sobti RC, Shekari M, Huria A: CpG island methylation of TMS1/ASC and CASP8 genes in cervical cancer. Eur J Med Res 2009;14:71-75.

-21 Zitt M, Zitt M, Muller HM: DNA methylation in colorectal cancer--impact on screening and therapy monitoring modalities? Dis Markers 2007;23:51-71.

22 Jeong DH, Youm MY, Kim YN, Lee KB, Sung MS, Yoon HK, Kim KT: Promoter methylation of p16, DAPK, CDH1, and TIMP-3 genes in cervical cancer: correlation with clinicopathologic characteristics. Int J Gynecol Cancer 2006;16:1234-1240.

23 Chung MT, Sytwu HK, Yan MD, Shih YL, Chang CC, Yu M H, Chu TY, Lai HC, Lin YW: Promoter methylation of SFRPs gene family in cervical cancer. Gynecol Oncol 2009;112:301-306.

24 Makitie T, Carpen O, Vaheri A and Kivela T: Ezrin as a prognostic indicator and its relationship to tumor characteristics in uveal malignant melanoma. Invest Ophthalmol Vis Sci 2001;42:2442-2449. 


\section{Cellular Physiology Cell Physiol Biochem 2018;50:277-287

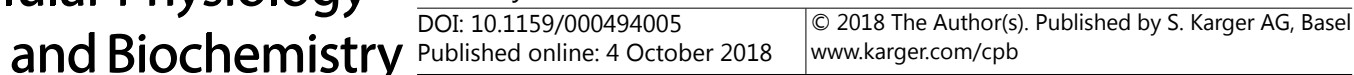 \\ Qin et al.: Ezrin Promoter Methylation and CC}

-25 Zacapala-Gómez AE, Navarro-Tito N, Alarcón-Romero LDC, Ortuño-Pineda C, IlladesAguiar B, Castañeda-Saucedo E, Ortiz-Ortiz J, Garibay-Cerdenares OL, Jiménez-López MA, Mendoza-Catalán MA: Ezrin and E-cadherin expression profile in cervical cytology: a prognostic marker for tumorprogression in cervical cancer. BMC Cancer 2018;18:349.

26 Yu Y, Davicioni E, Triche TJ, Merlino G: The homeoprotein six1 transcriptionally activates multiple protumorigenic genes but requires ezrin to promote metastasis. Cancer Res 2006;66:1982-1989.

27 Ogino W, Takeshima Y, Mori T, Yanai T, Hayakawa A, Akisue T, Kurosaka M, Matsuo M: High level of ezrin mRNA expression in an osteosarcoma biopsy sample with lung metastasis. J Pediatr Hematol Oncol 2007;29:435-439.

28 Li Q Gao H, Xu H, Wang X, Pan Y, Hao F, Qiu X, Stoecker M, Wang E, Wang E: Expression of ezrin correlates with malignant phenotype of lung cancer, and in vitro knockdown of ezrin reverses the aggressive biological behavior of lung cancer cells. Tumour Biol 2012;33:1493-1504.

-29 Huang HY, Li CF, Fang FM, Tsai J W, Li SH, Lee YT and Wei HM: Prognostic implication of ezrin overexpression in myxofibrosarcomas. Ann Surg Oncol 2010;17:3212-3219.

30 Kong J, Li Y, Liu S, Jin H, Shang Y, Quan C, Li Y, Lin Z: High expression of ezrin predicts poor prognosis in uterine cervical cancer. BMC Cancer 2013;13:520.

-31 Wentzensen N, Sherman M E, Schiffman M, Wang SS: Utility of methylation markers in cervical cancer early detection: appraisal of the state-of-the-science. Gynecol Oncol 2009;112:293-299.

32 Kirn V, Zaharieva I, Heublein S, Thangarajah F, Friese K, Mayr D, Jeschke U: ESR1 promoter methylation in squamous cell cervical cancer. Anticancer Res 2014;34:723-727.

-33 Zhang X, Zheng Z, Yingji S, Kim H, Jin R, Renshu L, Lee DY, Roh MR, Yang S: Downregulation of glutathione peroxidase 3 is associated with lymph node metastasis and prognosis in cervical cancer. Oncol Rep 2014;31:2587-2592.

-34 Lof-Ohlin Z M, Sorbe B, Wingren S and Nilsson T K: Hypermethylation of promoter regions of the APC1A and p16INK4a genes in relation to prognosis and tumor characteristics in cervical cancer patients. Int J Oncol 2011;39:683-688.

-35 Huang J, Liou YL, Kang YN, Tan ZR, Peng MJ, Zhou HH: Real-time colorimetric detection of DNA methylation of the PAX1 gene in cervical scrapings for cervical cancer screening with thiol-labeled PCR primers and gold nanoparticles. Int J Nanomedicine 2016;11:5335-5347.

-36 Zhu Y, Zhu MX, Zhang XD, Xu XE, Wu ZY, Liao LD, Li LY, Xie YM, Wu JY, Zou HY, Xie JJ, Li EM, Xu LY: SMYD3 stimulates EZR and LOXL2 transcription to enhance proliferation, migration, and invasion in esophageal squamous cell carcinoma. Hum Pathol 2016;52:153-63.

-37 Narayan K, McKenzie A F, Hicks R J, Fisher R, Bernshaw D, Bau S: Relation between FIGO stage, primary tumor volume, and presence of lymph node metastases in cervical cancer patients referred for radiotherapy. Int J Gynecol Cancer 2003;13:657-663.

-38 Ayhan A, Al RA, Baykal C, Demirtas E, Ayhan A, Yuce K: Prognostic factors in FIGO stage IB cervical cancer without lymph node metastasis and the role of adjuvant radiotherapy after radical hysterectomy. Int J Gynecol Cancer 2004;14:286-292.

-39 Kidd EA, Siegel BA, Dehdashti F, Rader JS, Mutch D G, Powell MA, Grigsby PW: Lymph node staging by positron emission tomography in cervical cancer: relationship to prognosis. J Clin Oncol 2010;28:21082113.

40 Blair PS, Winters SD, Armstrong GA, Low G, McCluggage WG, Grey AC: Re: the revised FIGO staging system for uterine malignancies: implications for MR imaging. Radiographics 2013;33:1520-1521. 